\title{
Advancement on mass transfer empirical models of electrodialysis regeneration for the liquid desiccant
}

\author{
Qing Cheng* and Lin Liu
}

\begin{abstract}
Liquid desiccant dehumidification has a large energy-saving potential in severe humid area. Electrodialysis regeneration is a novel and reliable liquid desiccant regeneration method, which can use the solar energy through photovoltaic panels and avoid desiccant droplets carried by supplied air from the environment during the regeneration. The current utilization coefficient and concentration increment are important performance evaluation indexes to reflect the mass transfer characteristic of the electrodialysis regenerator, which are influenced by the liquid desiccant flow rate seriously. This paper aims to acquire the current utilization coefficient and the concentration increment models considering the liquid desiccant flow rate. The results show that the current utilization coefficient increases with increasing the desiccant flow rate within the desiccant concentration of 30 and $34 \%$, while the increase of desiccant flow rate negatively affects the current utilization coefficient within the desiccant concentration of $38 \%$. The current utilization coefficients are among 30 and $90 \%$ under experimental conditions. The concentration increment which is among 0.06 and $0.33 \%$ increases with increasing the operating current and decreases with increasing the liquid desiccant flow rate addition. The whole system coefficient of performance increases from 2.4 to 3.6 when the desiccant solution flow rate varies from 80 to $160 \mathrm{~L} \cdot \mathrm{h}^{-1}$.
\end{abstract}

Keywords: Liquid desiccant; Regeneration; Electrodialysis; Current utilization coefficient; Concentration increment. Received: 28 April 2020; Accepted: 11 June 2020.

Article type: Research article.

\section{Introduction}

The comfortable and excellent air quality of indoor environment in buildings has become the important requirement nowadays. In buildings, the air-conditioning costs the large proportion of the total energy resources. ${ }^{[1]}$ At present, the vapor compression air-conditioning system is used to control the temperature and humidity of building indoor air, which decreases the air temperature for the air dehumidification and then reheats the air to meet the temperature requirement, ${ }^{[2,3]}$ resulting in the large consumption of fossil fuel and serious greenhouse gas emission.

The liquid desiccant air conditioning (LDAC) system can directly dehumidify indoor air as the desiccant solution can absorb vapor in air under the vapor pressure difference, ${ }^{[4-6]}$ which has a large energy-saving potential in severe humid area. In the LDAC system, the liquid desiccant regeneration device attributes to the main system energy consumption to

School of Energy Science and Engineering, Nanjing Tech University, Nanjing 211816, China.

Email: chengqingny@njtech.edu.cn (Q. Cheng) maintain the capacity for continuous dehumidification. Currently, there are different liquid desiccant regeneration ways in consideration. ${ }^{[7-8]}$ The conventional thermal regeneration includes condensing energy, solar energy and other thermal energy, among which the most popular one is the solar energy. ${ }^{[9]}$ However, the solar thermal energy depends on the weather, which may not meet the dehumidification demand continuously, especially with high air temperature or rainy day. ${ }^{[10]}$ On the other hand, the traditional thermal regeneration process needs liquid desiccant to contact outside environment air directly to acquire the high regeneration efficiency, while the desiccant droplets carried problem is difficult to be solved, which will affect room air quality and human healthy. ${ }^{[11]}$

Electrodialysis (ED) had been used for sea water desalination, wastewater treatment, and ion separation applications, which can be driven by the solar energy through photovoltaic panels. ${ }^{[12-14]}$ The ED regenerator encourages the anions and cations transport toward opposite directions and pass through different selective membranes to achieve the concentration of desiccant solution increase in concentrate cells under the electrical field. ${ }^{[15]} \mathrm{ED}$ regeneration is 
developed to regenerate liquid desiccant with solar energy under the hot and humid climate. When the environment air is hot and humid, liquid desiccant with high concentration is difficult to be regenerated with the conventional solar thermal regeneration method. In contrast, ED regeneration can acquire the strong liquid desiccant required in the dehumidifier even under the hot and humid climate, as this regeneration method does not need environment air. Then the weak liquid desiccant of the ED regenerator can be very easy to be regenerated by the conventional solar thermal regeneration method. Meanwhile, the problem of desiccant droplets corrosion can be avoided in the ED regenerator. Moreover, the ED regenerator can be operated with the relatively constant temperature, by this way the negative effect on the dehumidification process caused by the liquid desiccant temperature increment is eliminated. ${ }^{[16]}$

For the LDAC system, several researches had been conducted on ED regeneration. The solar ED regeneration method for liquid desiccant was firstly put forward by $\mathrm{Li}$ and Zhang. ${ }^{177,18]}$ Through the theoretical research, it was confirmed that solar ED regeneration has higher efficiency in comparison with the conventional thermal regeneration. Then ED regeneration driven by solar energy (photovoltaic) was gradually improved through several researches. ${ }^{[19-21]}$ Cheng et al. ${ }^{[22]}$ experimentally investigate the influence of concentration difference between dilute and concentrate desiccant solutions about the performance of ED regenerator, and the result shows that the concentration difference improvement has negative effect on the system performance. Han Wang et al. ${ }^{[23]}$ conducted the study on the electrical conductivity of $\mathrm{LiCl}$ solution with different concentrations and temperatures and obtained the accurate electrical conductivity model of $\mathrm{LiCl}$ solution.

The current utilization coefficient is important for the performance evaluation on the LDAC system based on ED regeneration, and it is also one of the important performance evaluation indexes to reflect the mass transfer characteristic of the ED regenerator. ${ }^{[11,10,22-25]}$ A simple current utilization coefficient model for $\mathrm{LiCl}$ solution was established by Cheng, ${ }^{[11]}$ which ignores the effect of liquid desiccant flow rate. As a result, the present current utilization coefficient model is not accurate enough to meet the demand of variable operational conditions as the variation of desiccant solution flow rate will change the flow state, thus affecting the mass transfer efficiency during the regeneration process. On the other hand, the concentration increment is also an important parameter, which had not been researched for the LDAC system models when $\mathrm{LiCl}$ solution is applied.

The novelty of this paper is:

- Develop the current utilization coefficient and the concentration increment empirical models of the ED regenerator considering liquid desiccant flow rate, which is beneficial to the application of ED regeneration in severe humid areas.

- Investigate the influence of liquid desiccant flow rate on the regeneration characteristic of the ED regenerator and the
LDAC system performance in depth, which is beneficial for the optimization design of electrodialysis regenerator in severe humid area.

\section{Method}

\subsection{Experimental preparation}

\subsubsection{System and material}

The ED experimental system in this work is displayed in Fig. 1 and Fig. 2(a). It shows that the system consists of three desiccant loops, including regenerate desiccant solution loop, dilute desiccant solution loop and electrode solution loop. In the experimental period, liquid desiccant solutions were pumped into different cells of the ED regenerator through three magnetic pumps, and the circulation flow rates in different loops were controlled by globe valves installed before flow meters.

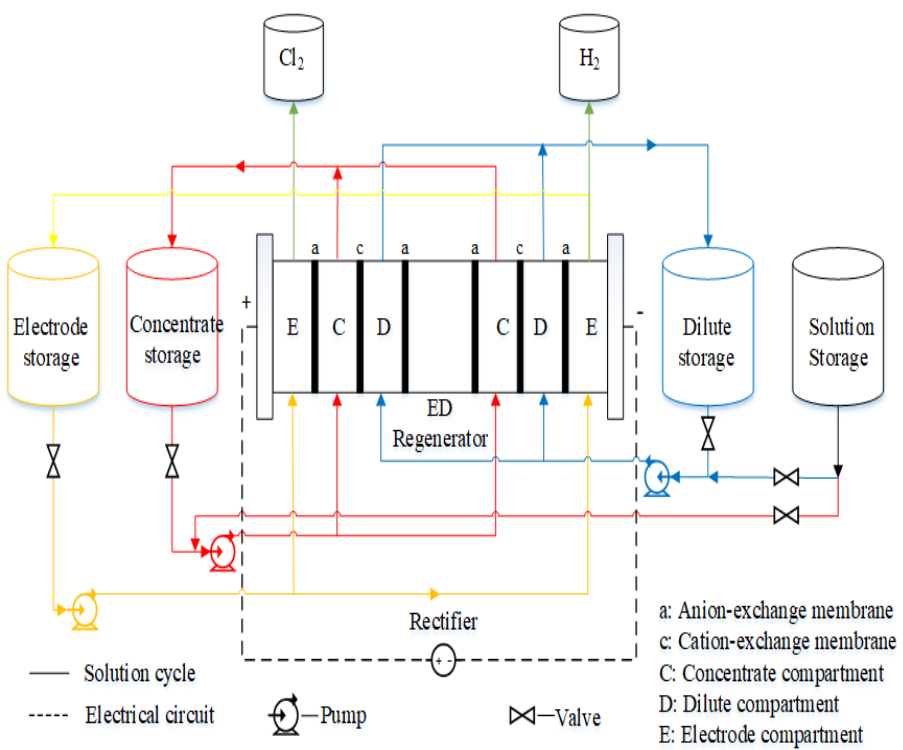

Fig. 1 The principle of the experimental system.

In this experimental system, the core device is the ED regenerator (shown in Fig. 2(b)), which is supplied by Zhejiang Yi Di Co., Ltd (SAAS-S, $200 \times 400 \mathrm{~mm}, 30$ cell pairs). Membranes in the experimental system are AMV and CMV from Asahi Nitrate in Japan, whose characteristic is shown in Table 1 . The electrode in the experimental system is coated with Titanium-Ruthenium.

Table 1. Membrane characteristics.

\begin{tabular}{cccc}
\hline Membrane & $\begin{array}{c}\text { Thickness } \\
(\mu \mathrm{m})\end{array}$ & $\begin{array}{c}\text { Resistance } \\
\left(\Omega \cdot \mathrm{cm}^{2}\right)\end{array}$ & Transport number \\
\hline CMV & 130 & 3 & $>0.96$ \\
AMV & 130 & 2.8 & $>0.96$ \\
\hline
\end{tabular}

The liquid desiccant in this experiment is $\mathrm{LiCl}$ solution from the Nanjing Jin Liu Hua Glass Instruments Co., Ltd.

\subsubsection{Measuring instruments}

In this experiment, the liquid desiccant temperature is measured with T-type thermocouple and recorded by the data 
collection equipment (Agilent 34970A). The mass concentration of the liquid desiccant is achieved through the density and temperature data. ${ }^{[26]}$ The real-time current and voltage can be acquired from the rectifier. The main instruments and their accuracies are summarized in Table 2.

Table 2. Instruments.

\begin{tabular}{llll}
\hline Name & Mode & $\begin{array}{l}\text { Measurement } \\
\text { range }\end{array}$ & Accuracy \\
\hline Rectifier & HCP- & $0-20 \mathrm{~A}$ & $\pm 0.01 \mathrm{~A}$ \\
& DC & & \\
Density meter & AU- & $0.0001-$ & $0.0001 \mathrm{~g} \cdot \mathrm{cm}^{-3}$ \\
& $120 \mathrm{~L}$ & $99.9999 \mathrm{~g} \cdot \mathrm{cm}^{-3}$ & \\
Thermocouple & TC-TT- & $-200-350^{\circ} \mathrm{C}$ & $\pm 0.5^{\circ} \mathrm{C}$ \\
& T-30- & & \\
& $5 \mathrm{M}$ & & \\
Flow meter & LFS15 & $16-160 \mathrm{~L} \cdot \mathrm{h}^{-1}$ & $\pm 5 \mathrm{~L}^{-1} \mathrm{~h}^{-1}$ \\
\hline
\end{tabular}

\subsubsection{Protocol}

In the experiment, 27 experimental conditions were conducted to research the current utilization coefficient and the concentration increment of the $\mathrm{ED}$ regeneration for $\mathrm{LiCl}$ solution. Three initial mass concentrations (30, 34 and 38\%) of the liquid desiccant and three operating current $(3,5$, and 8 A) were conducted. Meanwhile, three flow rates (80, 120 and $160 \mathrm{~L} \cdot \mathrm{h}^{-1}$ ) of the liquid desiccant were conducted in the experiment. During the experimental period, the liquid desiccant was sampled with intervals of six minutes from regenerate and dilute desiccant loops respectively for measuring their densities and temperatures.

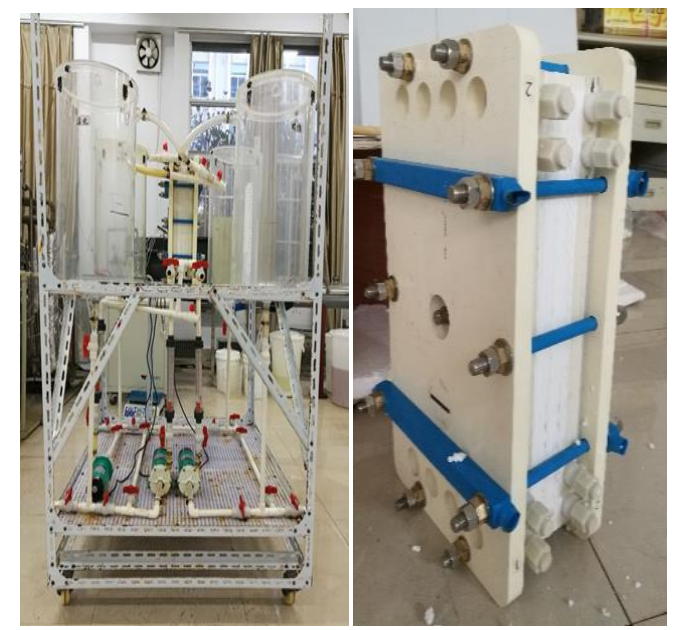

(a) The experimental system and (b) ED regenerator

Fig. 2 Devices in the experiment.

\subsection{Analytical methods}

The current utilization coefficient is the key performance evaluation index of the ED regenerator, ${ }^{[17,27]}$ which can be indicated as:

$$
\eta_{E D}=\frac{z F m_{r e g, E D}\left(C_{r e g, o}-C_{r e g, i}\right)}{I N M_{d}}
$$

The concentration increment of regenerate desiccant solution during the regeneration process of the ED regenerator can be acquired from:

$$
\Delta C=C_{\text {reg,o }}-C_{\text {reg, } i}
$$

So the exiting concentration of the regenerate desiccant solution of the $\mathrm{ED}$ regenerator is:

$$
C_{\text {reg,o }}=C_{\text {reg, } \mathrm{i}}+\Delta C
$$

The main energy consumption of the whole system can be expressed as Equation (4): ${ }^{[1]}$

$$
P=\left[\frac{z F m_{\text {reg }, E D}\left(C_{\text {reg }, o}-C_{\text {reg }, i}\right)}{\eta_{E D} N M_{d}}\right]^{2} N\left(R_{c m}+R_{a m}+\frac{L}{\rho_{\text {reg }} A}+\frac{L}{\rho_{\text {diu }} A}\right)
$$

The $\mathrm{LiCl}$ electrical conductivity can be acquired from Equation (5): ${ }^{[23]}$

$$
\begin{aligned}
\rho= & 160.5+3.058 \times \frac{T-38.59}{12.75}-28.96 \times \frac{C-29.51}{6.534}+0.9381 \times\left(\frac{T-38.59}{12.75}\right)^{2} \\
& +1.906 \times \frac{T-38.59}{12.75} \times \frac{C-29.51}{6.534}-6.32 \times\left(\frac{C-29.51}{6.534}\right)^{2}-0.3259 \times\left(\frac{T-38.59}{12.75}\right)^{3} \\
& -0.2426 \times\left(\frac{T-38.59}{12.75}\right)^{2} \times \frac{C-29.51}{6.534}+0.3203 \times \frac{T-38.59}{12.75} \times\left(\frac{C-29.51}{6.534}\right)^{2} \\
& +2.091 \times\left(\frac{C-29.51}{6.534}\right)^{3}
\end{aligned}
$$

The system refrigerating capacity can be achieved from the water vaporization heat during the dehumidification process: $[18,28]$

$$
\mathrm{Q}_{\mathrm{o}}=\mathrm{r}_{\mathrm{w}} \Delta \mathrm{m}_{\mathrm{w}}
$$

The moisture removal rate in the dehumidification process for the $\mathrm{LiCl}$ solution can be acquired from Equation (7):[29]

$$
\Delta m_{w}=9.4542 \times 10^{8} \times m_{\mathrm{a}}^{0.406} \omega_{\mathrm{a}}^{2.2478} m_{\mathrm{reg}}^{0.6499} t_{\mathrm{rega}}^{-2.3911} C_{\mathrm{reg}}^{1.7919}
$$

Based on Equations (6) and (7):

$$
\mathrm{Q}_{\mathrm{o}}=9.4542 \times 10^{8} \times m_{\mathrm{a}}^{0.406} \omega_{\mathrm{a}}^{2.2478} m_{\mathrm{reg}}^{0.6499} t_{\mathrm{rega}}^{-2.3911} C_{\mathrm{reg}}^{1.7919} r_{w}
$$

As a consequence, the system performance coefficient can be given by combing Equations (4) and (8):

$$
C O P=\frac{9.4542 \times 10^{8} \times m_{a}^{0.406} \omega_{a}^{2.2478} m_{r e g}^{0.6499} t_{r e g}^{-2.3911} C_{r e g}^{1.7919} r_{w}}{\left[\frac{z F m_{r e g, E D}\left(\mathrm{C}_{r e g, o}-C_{r e g, i}\right)}{\eta_{E D} N M_{d}}\right]^{2} N\left(R_{c m}+R_{a m}+\frac{L}{\rho_{r e g} A}+\frac{L}{\rho_{\text {diu }} A}\right)}
$$

The dehumidification efficiency and the income-cost coefficient can be achieved from:

$$
\eta_{d e}=\frac{\Delta m_{w}}{P}=\frac{9.4542 \times 10^{8} \times m_{a}^{0.406} \omega_{a}^{2.2478} m_{r e g}^{0.6499} t_{r e g}^{-2.3911} C_{\text {reg }}^{1.7919}}{\left[\frac{z F m_{r e g, E D}\left(\mathrm{C}_{r e g, o}-C_{r e g, i}\right)}{\eta_{E D} N M_{d}}\right]^{2} N\left(R_{c m}+R_{\text {am }}+\frac{L}{\rho_{\text {reg }} A}+\frac{L}{\rho_{\text {diu }} A}\right)}
$$

$$
I C C=\frac{\Delta p}{P}=\frac{p_{\text {air }}-p}{\left[\frac{z F m_{r e g, E D}\left(\mathrm{C}_{r e g, o}-C_{r e g, i}\right)}{\eta_{E D} N M_{d}}\right]^{2} N\left(R_{c m}+R_{a m}+\frac{L}{\rho_{r e g} A}+\frac{L}{\rho_{d i u} A}\right)}
$$




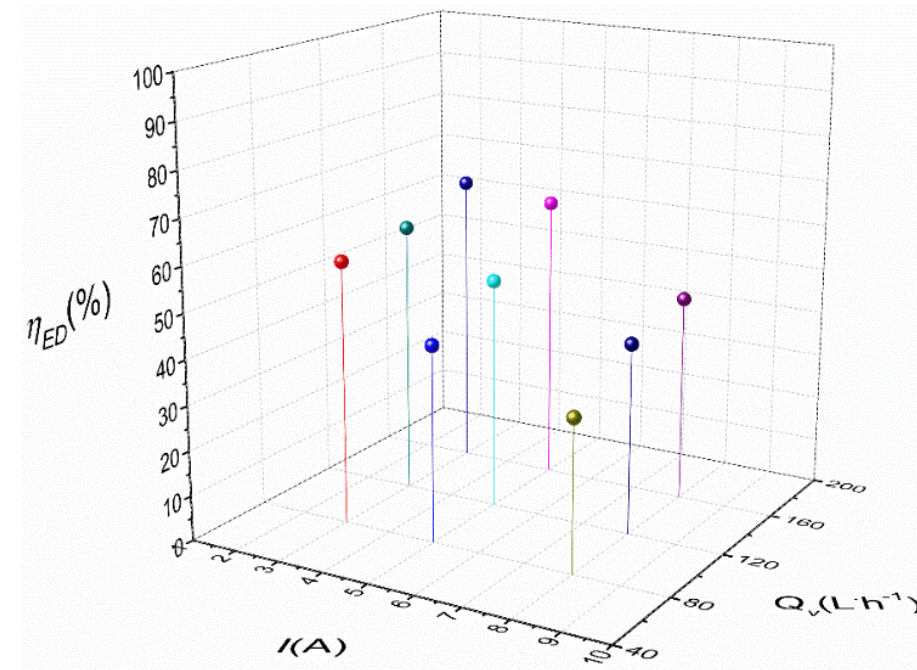

(a) Initial concentration of 30\%

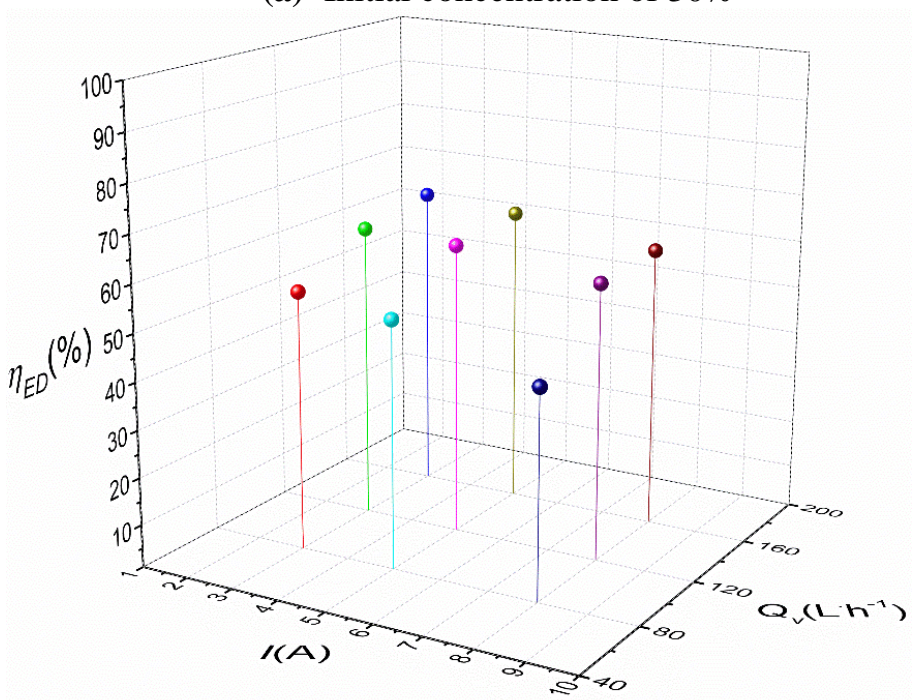

(b) Initial concentration of 34\%

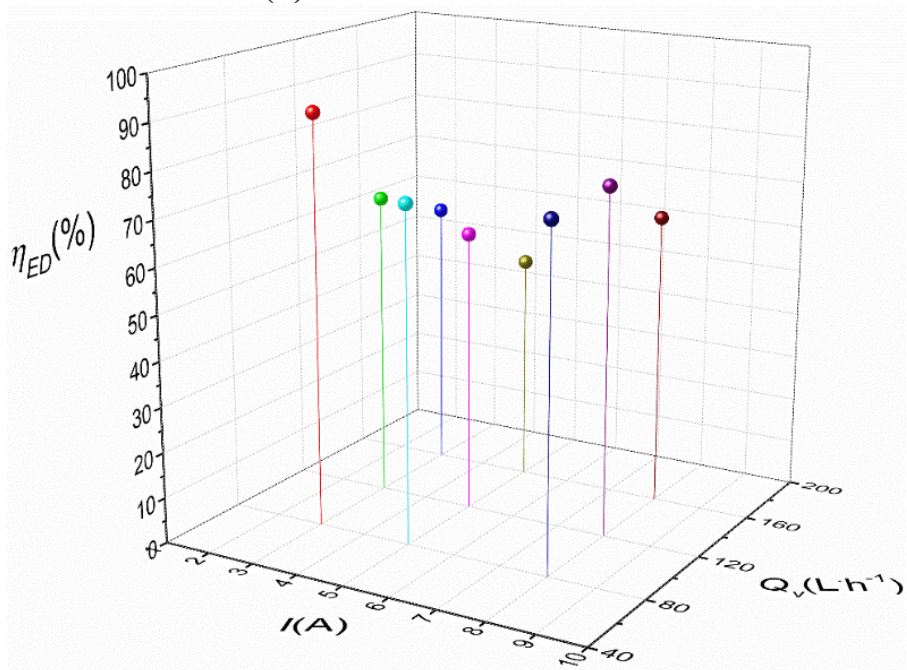

(c). Initial concentration of $38 \%$

Fig. 3 The average system current utilization coefficients with three initial concentrations

\section{Experimental result and characteristic model}

\subsection{The current utilization coefficient correlation}

In the experiment analysis process, the average values of the calculated current utilization coefficients are obtained to appraise the ED regenerator performance under specific operating conditions, which are shown in Fig. 3. In Fig.3, the $\mathrm{x}$-axis and $\mathrm{y}$-axis represent operating current and desiccant flow rate respectively

Fig. 3(a) shows that with the initial $\mathrm{LiCl}$ solution concentration of $30 \%$, the average current utilization coefficients under different operating conditions in the experiment are among 33.8 and $65.4 \%$. It is shown that the average current utilization coefficient decreases with the operating current addition while increases with increasing the $\mathrm{LiCl}$ solution flow rate. The maximum average system current utilization coefficient is $65.4 \%$ with the operating current of $3 \mathrm{~A}$ and the $\mathrm{LiCl}$ solution flow rate of $160 \mathrm{~L} \cdot \mathrm{h}^{-1}$. The minimum average system current utilization coefficient is $33.8 \%$ with the operational current of $8 \mathrm{~A}$ and the $\mathrm{LiCl}$ solution flow rate of $80 \mathrm{~L} \cdot \mathrm{h}^{-1}$.

Fig. 3(b) shows that when the initial $\mathrm{LiCl}$ solution concentration is $34 \%$, the average current utilization coefficients of all conditions in the experiment are among 44.9 and $65.9 \%$, and its variation trend is the same with that when the initial $\mathrm{LiCl}$ solution concentration is $30 \%$. The average system current utilization coefficient decreases with the operating current addition and increases with the $\mathrm{LiCl}$ solution flow rate improvement.

Fig. 3(c) shows that with the initial $\mathrm{LiCl}$ solution concentration of $38 \%$, the average system current utilization coefficients of different operational conditions in the experiment are among 50.2 and $90.2 \%$. Different with the variation trend when desiccant mass concentrations are 30 and $34 \%$, the average system current utilization coefficient with the initial desiccant concentration of $38 \%$ decreases with the operating current addition and slightly decreases with the $\mathrm{LiCl}$ solution flow rate improvement. The maximum average system current utilization coefficient is $90.2 \%$ with the operating current of $3 \mathrm{~A}$ and the $\mathrm{LiCl}$ solution flow rate of $80 \mathrm{~L} \cdot \mathrm{h}^{-1}$. The minimum average system current utilization coefficient is $50.2 \%$ with the operating current of $8 \mathrm{~A}$ and the $\mathrm{LiCl}$ solution flow rate of $160 \mathrm{~L} \cdot \mathrm{h}^{-1}$.

According to Levenberg-Marquardt algorithm method, the poly $2 \mathrm{D}$ function is used in nonlinear curve fitting. The current utilization coefficient correlation model with the initial $\mathrm{LiCl}$ solution concentration of $30 \%$ is:

$$
\begin{aligned}
\eta_{\mathrm{ED}} & =65.1057-5.86372 \times I+0.0477 \times Q_{\mathrm{v}}+0.05737 \times I^{2} \\
& +2.69958 \times 10^{-4} \times Q_{\mathrm{v}}{ }^{2}+0.00935 \times I Q_{\mathrm{v}}
\end{aligned}
$$

The current utilization coefficient correlation model with the initial $\mathrm{LiCl}$ solution concentration of $34 \%$ is:

$$
\begin{aligned}
\eta_{\mathrm{ED}} & =15.27173-0.97707 \times I+0.73601 \times Q_{\mathrm{v}}-0.18756 \times I^{2} \\
& -0.00274 \times Q_{\mathrm{v}}{ }^{2}+0.01409 \times I Q_{\mathrm{v}}
\end{aligned}
$$


And the current utilization coefficient correlation model with the initial $\mathrm{LiCl}$ solution concentration of $38 \%$ is:

$$
\begin{aligned}
\eta_{\mathrm{ED}} & =180.73326-24.79161 \times I-0.58905 \times Q_{\mathrm{v}}+1.68421 \times I^{2} \\
& +1.79968 \times Q_{\mathrm{v}}{ }^{2}+0.05169 \times I Q_{\mathrm{v}}
\end{aligned}
$$

As a consequence, the current utilization coefficient at the same position in the three models is correlated and then substituted into the poly 2D function to acquire the integral model of the system current utilization coefficient: $\eta_{\mathrm{ED}}=7301.4789-443.05362 \times C_{\text {reg. } \mathrm{i}}+6.72804 \times C_{\mathrm{reg}, \mathrm{i}}^{2}-957.36403 \times I$

$$
\begin{aligned}
& +58.62404 \times C_{\text {reg, } i} I-0.89691 \times C_{\text {reg, }}^{2} I-69.29079 \times Q_{\mathrm{v}} \\
& +4.19882 \times C_{\text {reg, }} Q_{v}-0.06292 \times C_{\text {reg, }}^{2} Q_{\mathrm{v}}+69.36416 \times I^{2} \\
& -4.29463 \times C_{\text {reg. } .1} I^{2}+0.06615 \times C_{\text {reg. }}^{2} I^{2}+0.21186 \times Q_{\mathrm{v}}{ }^{2} \\
& -0.01261 \times C_{\text {reg, },} Q_{\mathrm{v}}{ }^{2}+1.85309 \times 10^{-4} \times C_{\text {reg, },}^{2} Q_{\mathrm{v}}{ }^{2} \\
& +1.02121 \times I Q_{\mathrm{v}}-0.06454 \times C_{\text {reg, } \mathrm{i}} I Q_{\mathrm{v}}+0.00103 \times C_{\text {reg, } \mathrm{i}}^{2} I Q_{\mathrm{v}}
\end{aligned}
$$

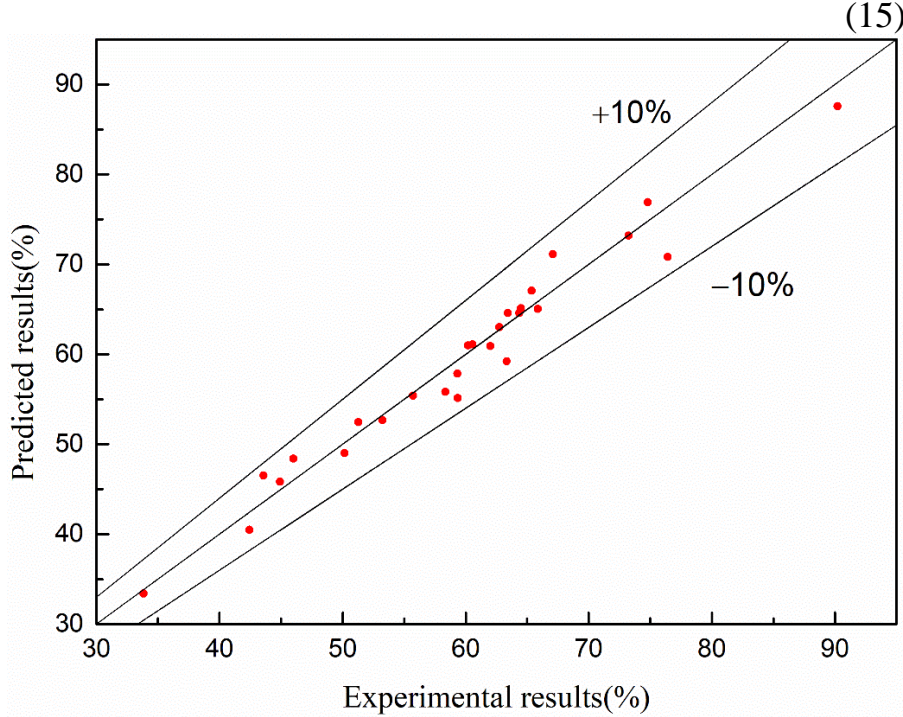

Fig. 4 Comparison of the predicted system current utilization coefficient and experimental results.

The adjusted R-Square of the system current utilization coefficient correlation model is $80.741 \%$. Fig. 4 shows the comparison of fitted system current utilization coefficients and experimental results. It can be concluded that the average absolute difference of current utilization coefficient experimental and predicted values is below $\pm 10 \%$, which shows the accuracy of this current utilization coefficient model. As this current utilization coefficient model is based on experimental results, the using scope of this model is the concentration range of $30-38 \%$, the mass flow rate range of $80-160 \mathrm{~L} / \mathrm{h}$ and the current range of 3-8 A.

\subsection{The concentration increment correlation}

In this experiment, the concentration of exiting regenerated desiccant is calculated with Equation (3) based on the experimental data, meanwhile, average values of the calculated exiting regenerate desiccant concentration are obtained and shown in Fig. 5. Fig. 5 shows the average concentration increment of regenerate desiccant in the experiment. Average concentration increments under all operating conditions in the experiment are among 0.06 and $0.33 \%$. It is shown that the average concentration increment of regenerate desiccant solution increases with the operating current addition and decreases with the $\mathrm{LiCl}$ solution flow rate improvement. On the other hand, the average concentration increment of regenerate desiccant solution decreases with the $\mathrm{LiCl}$ solution initial concentration improvement. The maximum average concentration increment is $0.33 \%$ with the operating current of $8 \mathrm{~A}$ and the $\mathrm{LiCl}$ solution flow rate of $80 \mathrm{~L} \cdot \mathrm{h}^{-1}$. The minimum average concentration increment is $0.06 \%$ as the operating current is $3 \mathrm{~A}$ and the $\mathrm{LiCl}$ solution flow rate of $160 \mathrm{~L} \cdot \mathrm{h}^{-1}$.

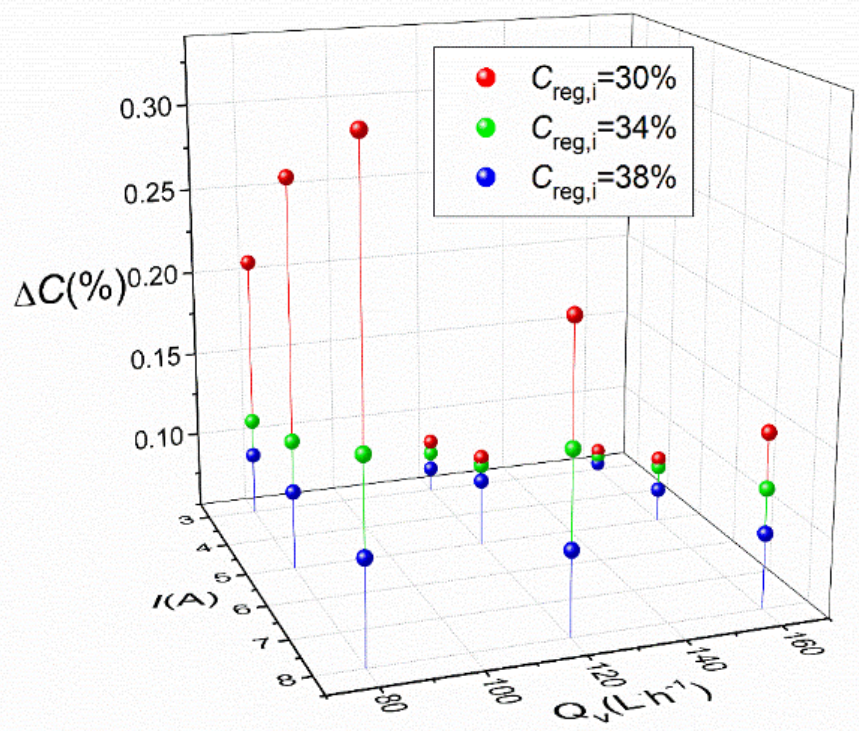

Fig. 5 The average concentration increment in the experiment.

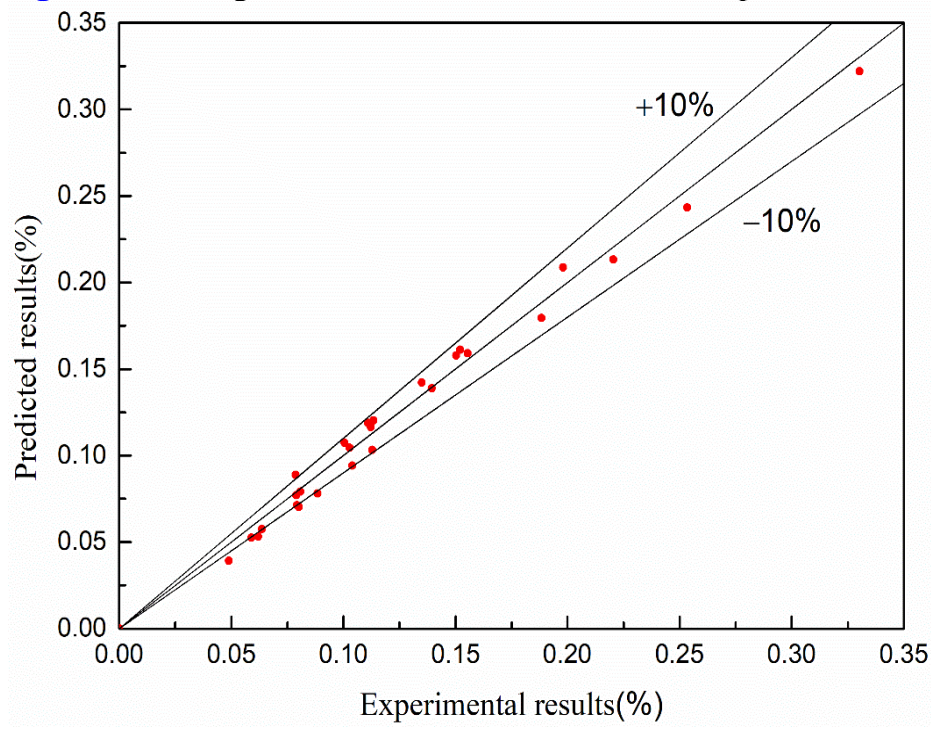

Fig. 6 Comparison of the predicted concentration increment and experimental results.

According to the Levenberg-Marquardt algorithm method, the concentration increment of regenerate desiccant solution model can be expressed as: 


$$
\Delta C=1.028913 \times 10^{6} \times C_{\mathrm{reg}, \mathrm{i}}^{-3.45874} \cdot I^{0.59592} \cdot Q_{\mathrm{v}}^{-1.01617}
$$

Then the concentration of exiting regenerate desiccant can be obtained with Equation (3). As this model is based on experimental results, the using scope of this model is the concentration range of $30-38 \%$, the mass flow rate range of $80-160 \mathrm{~L} / \mathrm{h}$ and the current range of 3-8 A.

The adjusted R-Square of this average concentration increment of regenerate desiccant solution correlation model is $87.66 \%$. Fig. 6 shows the comparison of the predicted concentration increment and experimental results. It can be concluded that average absolute difference among experimental concentration increments of regenerate desiccant solution and predicted values is also below $\pm 10 \%$.

4. The regeneration characteristic and system performance evaluation

In this simulation section, whole system consumption, whole system COP, income-cost coefficient and system dehumidification efficiency are evaluated with Equations (4) and (9-11). In this simulation part, the ED experimental regenerator shown in this paper and the specific dehumidifier presented in the reference ${ }^{[29]}$ are conducted. However, just one ED experimental regenerator shown in this paper is not enough to satisfy the demand of dehumidifier presented in the reference [29]. Thus several same ED regenerators shown in this paper are conducted to provide strong $\mathrm{Li} \mathrm{Cl}$ solution for the specific dehumidifier presented in the reference [29]. The simulation settings are listed in Table 3 .

Table 3. General parameters.

\begin{tabular}{ccc}
\hline Parameter & value & specification \\
\hline $\mathrm{Z}$ & 1 & $\mathrm{LiCl}$ \\
$F\left(\mathrm{C} \cdot \mathrm{mol}^{-1}\right)$ & 96485 & \\
$M_{d}\left(\mathrm{~g} \cdot \mathrm{mol}^{-1}\right)$ & 42.5 & $\mathrm{LiCl}$ \\
$L(\mathrm{~mm})$ & 1 & experimental system \\
$A\left(\mathrm{~m}^{2}\right)$ & 0.048 & experimental system \\
$N$ & 30 & experimental system \\
$r_{\mathrm{w}}\left(\mathrm{kJ} \cdot \mathrm{kg}^{-1}\right)$ & 2257.2 & \\
$m_{\mathrm{a}}\left(\mathrm{kg} \cdot \mathrm{s}^{-1}\right)$ & 0.3 & {$[29]$} \\
$\omega_{\mathrm{a}}\left(\mathrm{g} \cdot \mathrm{kg}^{-1}\right)$ & 16.5 & {$[29]$} \\
$m_{\mathrm{reg}}\left(\mathrm{kg} \cdot \mathrm{s}^{-1}\right)$ & 0.4 & {$[29]$} \\
$t_{\mathrm{reg}}\left({ }^{\circ} \mathrm{C}\right)$ & 30 & experimental system \\
\hline
\end{tabular}

The system current utilization coefficient and the concentration increment of regenerate desiccant solution models are simulated with variable parameters shown in Table 4.

Table 4. Variable parameters.

\begin{tabular}{|c|c|c|c|}
\hline Simulation & 1 & 2 & 3 \\
\hline$C_{\text {reg, } \mathrm{i}}(\%)$ & 34 & 34 & $30-38$ \\
\hline$I(\mathrm{~A})$ & 5 & $3-8$ & 5 \\
\hline$Q_{\nu}\left(\mathrm{L} \cdot \mathrm{h}^{-1}\right)$ & $80-160$ & 120 & 120 \\
\hline
\end{tabular}

\subsection{The regeneration characteristic}

Fig. 7 shows the influence of the $\mathrm{LiCl}$ solution flow rate on the current utilization coefficient and the concentration increment of regenerate desiccant solution. It shows that with the $\mathrm{LiCl}$ solution flow rate improvement, the system current utilization coefficient increases and the concentration increment of regenerate desiccant solution decreases. The current utilization coefficient varies from 52 to $64 \%$ and the concentration increment varies from 0.16 to $0.08 \%$ as $\mathrm{LiCl}$ solution flow rate increases from 80 to $160 \mathrm{~L} \cdot \mathrm{h}^{-1}$.

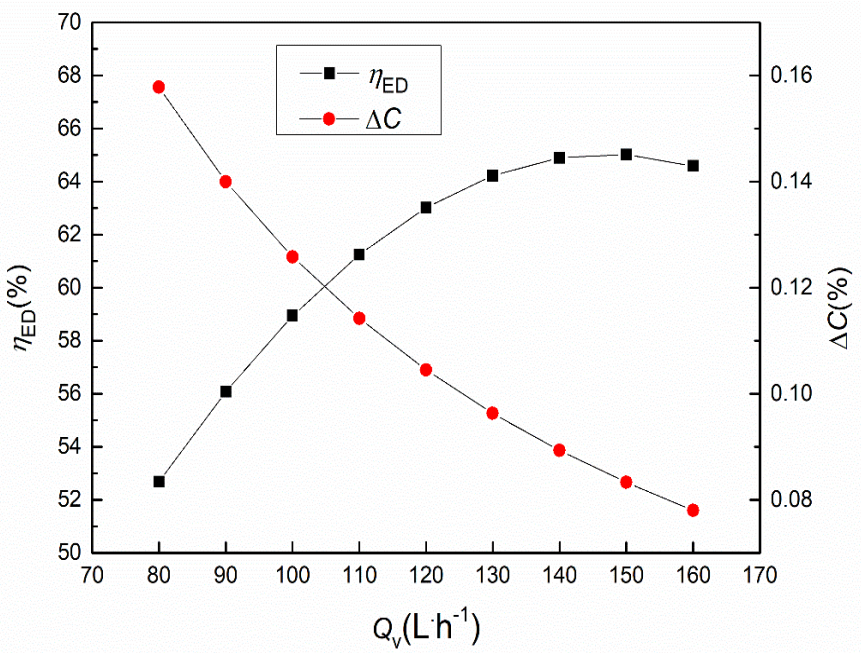

Fig. 7 Effect of $\mathrm{LiCl}$ flow rate on current utilization coefficient and concentration increment.

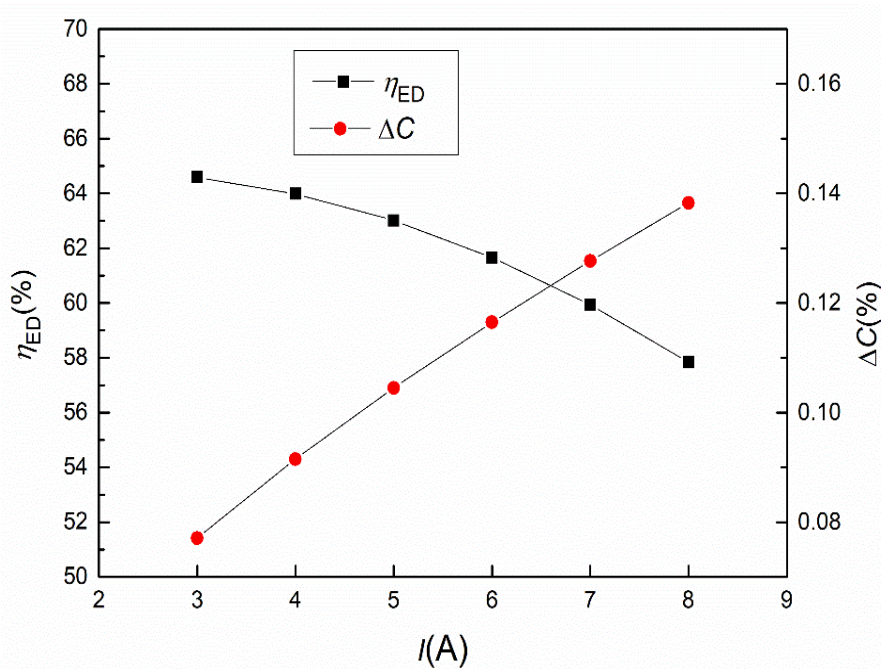

Fig. 8 Effect of operating current on current utilization coefficient and concentration increment.

The influence of operating current on the system current utilization coefficient and the concentration increment of regenerate desiccant solution is shown in Fig. 8. It can be concluded that with the operating current improvement, the current utilization coefficient decreases while the concentration increment of regenerate desiccant solution increases. It shows that the system current utilization coefficient varies from 64 to $57 \%$ and the concentration increment of regenerate desiccant solution varies from 0.08 to $0.14 \%$ when the operating current increases from 3 to $8 \mathrm{~A}$. 


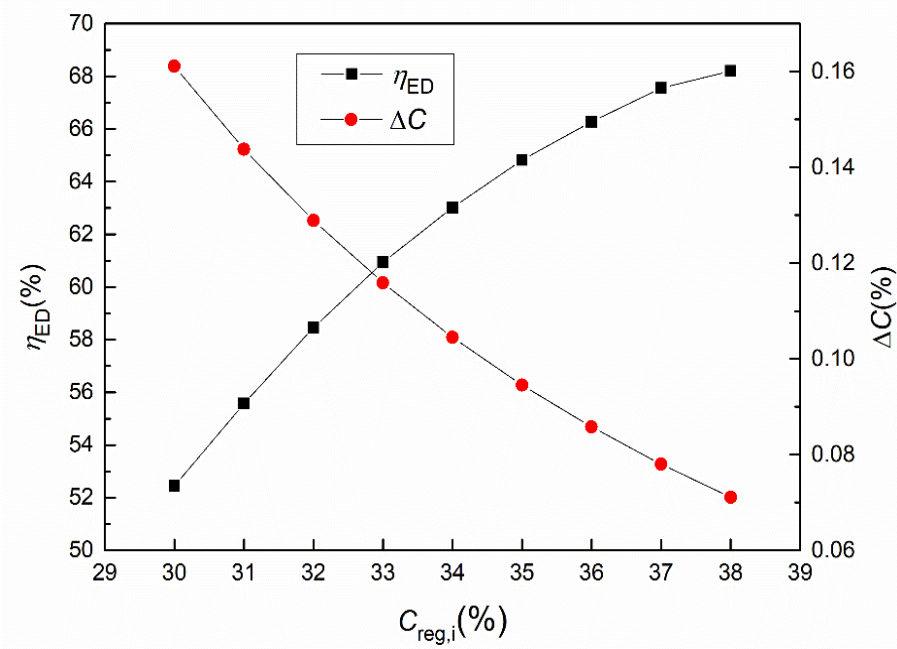

Fig. 9 Effect of initial concentration on current utilization coefficient and concentration increment.

Fig. 9 shows the effect of initial $\mathrm{LiCl}$ solution concentration on the current utilization coefficient and the concentration increment of regenerate desiccant solution. It shows that with the initial $\mathrm{LiCl}$ solution concentration improvement, the current utilization coefficient increases while the concentration increment decreases. The system current utilization coefficient varies among 52 and $68 \%$ and the concentration increment of regenerate desiccant solution varies among 0.16 and $0.07 \%$ when the initial concentration of the regenerate and dilute $\mathrm{LiCl}$ solutions increases from 30 to $38 \%$.

\subsection{System performance evaluation}

The influence of $\mathrm{LiCl}$ solution flow rate on the system performance is analyzed with simulation 1 in the Table 4. Fig. 10(a) shows the effect of $\mathrm{LiCl}$ solution flow rate on the electrical energy cost and the COP of the whole system, and its influence on income-cost coefficient and dehumidification efficiency is displayed in Fig. 10(b).

Fig. 10(a) shows that with the $\mathrm{LiCl}$ solution flow rate improvement, the electrical energy cost of ED regenerator decreases and the system COP increases. The system electrical energy consumption varies from 1030 to $655 \mathrm{~W}$ and the system COP varies from 2.9 to 4.6 when the $\mathrm{LiCl}$ solution flow rate increases from 80 to $160 \mathrm{~L} \cdot \mathrm{h}^{-1}$. The $\mathrm{LiCl}$ solution flow rate improvement will be beneficial to the current utilization coefficient because the large $\mathrm{LiCl}$ solution flow rate may destroy the ion diffusion boundary layers and accelerate the mass transfer. Although the electrical energy consumption of the single ED regenerator increases slightly with the $\mathrm{LiCl}$ solution flow rate improvement, there will be fewer number of ED regenerator operating simultaneously needed to meet the dehumidifier demand. Thus, the $\mathrm{LiCl}$ solution flow rate improvement will lead to the whole system electrical energy consumption reduction and increase the whole system $C O P$.

It can be concluded from Fig. 10(b) that the income-cost coefficient and the dehumidification efficiency increase with the $\mathrm{LiCl}$ solution flow rate improvement. The income-cost coefficient varies from 2.4 to $3.7 \mathrm{~Pa} \cdot \mathrm{W}^{-1}$ and the system dehumidification efficiency varies from 4.7 to $7.3 \mathrm{~kg} \cdot \mathrm{kWh}^{-1}$ when the $\mathrm{LiCl}$ solution flow rate increases from 80 to 160 $\mathrm{L} \cdot \mathrm{h}^{-1}$.

In conclusion, with the $\mathrm{LiCl}$ solution flow rate improvement, the system dehumidification capacity will increase while the system energy consumption will decrease. As a consequence, the $\mathrm{LiCl}$ solution flow rate improvement is beneficial to the whole system performance.

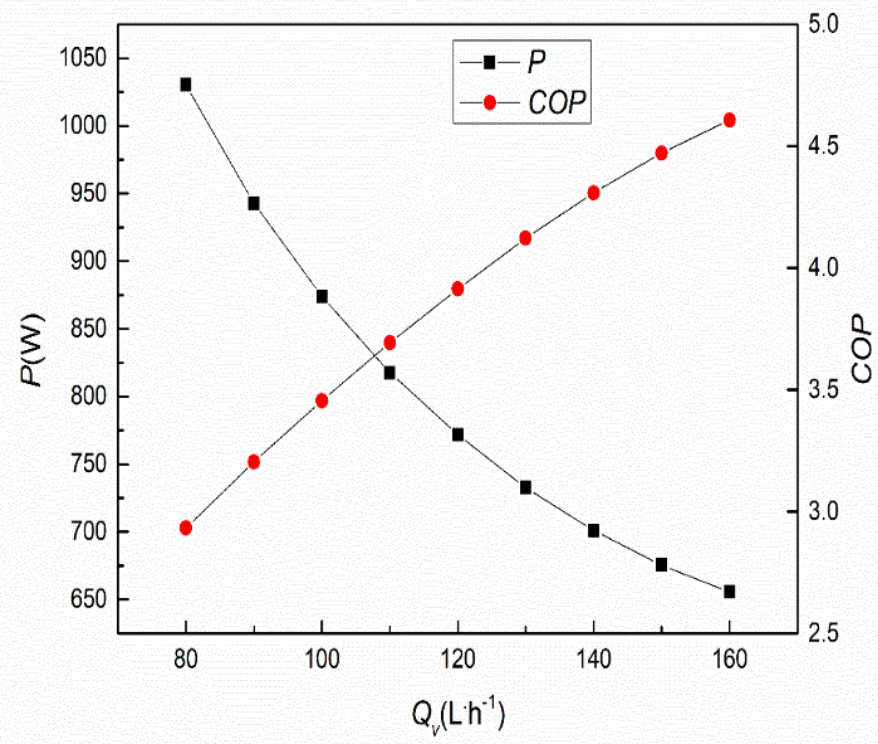

(a) Energy consumption and COP

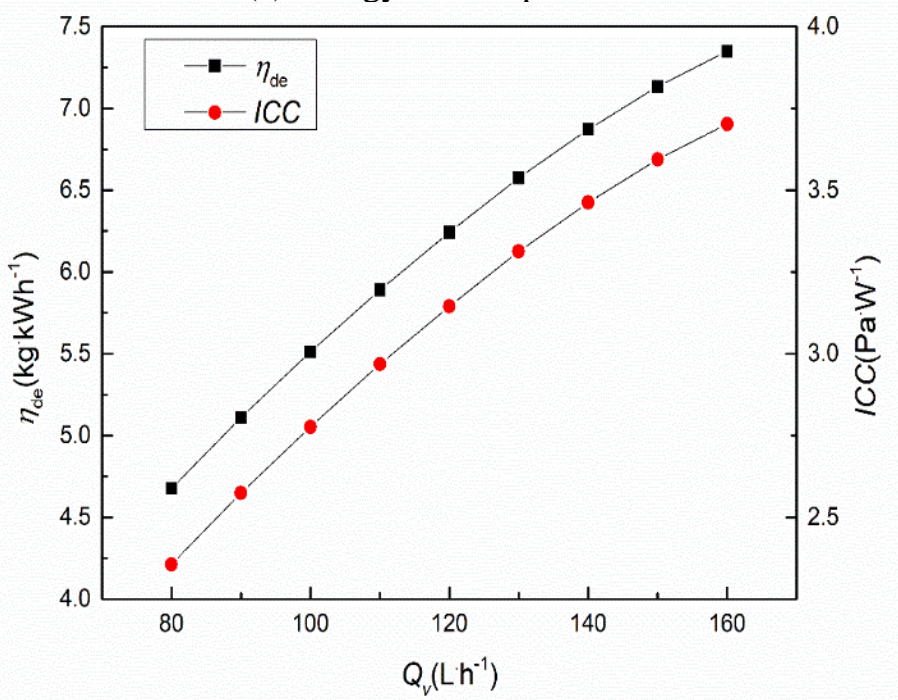

(b) Dehumidification performance

Fig. 10 Effect of $\mathrm{LiCl}$ solution flow rate on system performance.

\subsection{Discussion}

The results show that the current utilization coefficient increases with increasing the desiccant flow rate within the desiccant concentration of 30 and $34 \%$, while the increase of desiccant flow rate negatively affects the current utilization coefficient within the desiccant concentration of $38 \%$. This is an interesting phenomenon and it may be because of the high viscosity characteristic of $\mathrm{LiCl}$ solution with the 
concentration of $38 \%$, which should be further theoretically researched in the future work to explore the mass transfer characteristic of liquid desiccant with the extra high concentration in ED regeneration. Meanwhile, liquid desiccant nature modification should also be researched to reduce the effect of the high viscosity characteristic.

The result shows that the increase of $\mathrm{LiCl}$ solution flow rate will increase the performance coefficient of the liquid desiccant air-conditioning system based on ED regeneration, which will also decrease the energy consumption of the liquid desiccant air-conditioning system, so it's necessary to increase the liquid desiccant flow rate to improve the system performance. However, the increase of $\mathrm{LiCl}$ solution flow rate will decrease the concentration increment of the ED regenerator, so it's necessary to increase the cell pairs of the $\mathrm{ED}$ regenerator to meet the concentration requirement of dehumidification part. In the analysis of system energy cost, although the $\mathrm{LiCl}$ solution flow rate improvement will increase the electrical energy cost of single ED regenerator slightly, the ED regenerator number needed to meet the dehumidifier requirement will be reduced. Thus, the $\mathrm{LiCl}$ solution flow rate improvement is beneficial to energy consumption and COP. As a result, the $\mathrm{LiCl}$ solution flow rate should be designed to be maximized when the regenerated liquid desiccant can meet the dehumidification requirement. On the other hand, the electrical energy cost of solution pumps will increase with the $\mathrm{LiCl}$ solution flow rate improvement, which is ignored in this paper, so it's essential to advance the system model integrated with the pump energy cost based on the desiccant solution flow rate consideration in the future work. Besides, the liquid desiccant flow state in the compartment will be changed from laminar flow to turbulent flow and the pressure will be increased due to desiccant flow rate improvement, which will affect the mass transfer process.

\section{Conclusion}

Average current utilization coefficients are among 30 and $90 \%{ }^{r_{\mathrm{w}}}$ in this experiment. The current utilization coefficient increases with the $\mathrm{LiCl}$ solution flow rate improvement while decreases with the current addition with the initial $\mathrm{LiCl}$ solution concentration of 30 and $34 \%$, while the $\mathrm{LiCl}$ solution flow rate improvement will decrease the current utilization coefficient with the initial concentration of $38 \%$. Average concentration increments of regenerate desiccant solution are among 0.06 and $0.33 \%$ in the experiment. It is shown that the average concentration increment of regenerate desiccant solution increases with the operating current improvement and decreases with the $\mathrm{LiCl}$ solution flow rate improvement. On the other hand, the average concentration increment of regenerate desiccant solution of ED regenerator decreases with the initial $\mathrm{LiCl}$ solution concentration improvement.

In the simulation, the whole system COP varies among 2.4 and 3.6 with the $\mathrm{LiCl}$ solution flow rate varying from 80 to $160 \mathrm{~L} \cdot \mathrm{h}^{-1}$. The liquid desiccant flow rate improvement is beneficial to the energy consumption and COP, so it should be designed to be maximized when the regenerated liquid desiccant solution can meet the dehumidification requirement.

\section{Acknowledgments}

This research work in this paper was supported by the Postdoctoral Research Funding Program of Jiangsu Province (No.2019K288) and National Natural Science Foundation of China (No. 51506083).

\section{Support information}

Not applicable

\section{Conflict of Interest}

There are no conflicts to declare.

\section{Nomenclature}

A

$C$

COP

F

I

ICC

$L$

$m_{\mathrm{a}}$

$m_{\text {reg }}$

$m_{\text {reg,ED }}$

$M_{d}$

$N$

$P$

$p_{\text {air }}$

$P$

$Q_{0}$

$Q_{v}$

\section{$R$}

$t_{\text {reg }}$

$T$

$\mathrm{Z}$

valence

moisture transfer in the dehumidifier $\left(\mathrm{g} \cdot \mathrm{s}^{-1}\right)$

$\eta_{\mathrm{de}} \quad$ system dehumidification efficiency

$\left(\mathrm{kg} \cdot \mathrm{kWh}^{-1}\right)$

current utilization coefficient (\%)

electrical conductivity $\left(\mathrm{mS} \cdot \mathrm{cm}^{-1}\right)$

the humidity ratio of air $\left(\mathrm{kg} \cdot \mathrm{kg}^{-1}\right)$

Subscripts

$\mathrm{Am}$

$\mathrm{Cm}$ anion-exchange membrane cation-exchange membrane 
Diu

Reg

reg,i

reg,o dilute desiccant regenerate desiccant entering regenerate desiccant exiting regenerate desiccant

\section{References:}

[5] A. A. Al-Farayedhi, P. Gandhidasan, S. Younus Ahmed, Energy Convers. Manag., 1999, 40, 1405-1411, doi: doi.org/10.1016/S0196-8904(99)00036-9.

[6] S. Misha, S. Mat, M. H. Ruslan, K. Sopian, Renew. Sustain. Energy Rev., 2012, 16, 4686-4707, doi: 10.1016/j.rser.2012.04.041.

[7] F. Armanasco, L. P. M Colombo, A. Lucchini, A. Rossetti, Int. J. Refrig., 2015, 53, 163-176, doi; 10.1016/j.ijrefrig.2015.01.008.

[8] R. Qi, L. Lu, Y. Huang, Energy Convers. Manag., 2014, 88, 749-757, doi: 10.1016/j.enconman.2014.09.006

[9] D. Peng, X. Zhang, Int. J. Refrig., 2015, 49, 151-159, doi: 10.1016/j.ijrefrig.2014.10.004.

[10] Q. Cheng, W. Xu, Energy 2017, 140, 240-252, doi: 10.1016/j.energy.2017.08.092

[11] Q. Cheng, S. Jiao, Int. J. Refrig., 2018, 96, 1-9, doi: doi.org/10.1016/j.ijrefrig.2018.09.001

[12] K. Bawornruttanaboonya, S. Devahastin, T. Yoovidhya, N. Chindapan, J. Food Eng., 2015, 159, 76-85. Doi: 10.1016/j.jfoodeng.2015.03.014.

[13] A. H. Galama,., M. Saakes, H. Bruning, H. H. M. Rijnaarts, J. W. Post, Desalination, 2014, 342, 61-69, doi: 10.1016/j.desal.2013.07.012.

[14] D. Valero, V. García-García, E. Expósito, A. Aldaz, V. Montiel, J. Membr. Sci., 2015, 476, 580-589 doi: 10.1016/j.memsci.2014.11.007.

[15] A. Ali, R. A. Tufa, F. Macedonio, E. Curcio, E. Drioli, Renew. Sustain. Energy Rev., 2018, 81, 1-21 doi: 10.1016/j.rser.2017.07.047.

[16] Y. Guo, Z. Ma, A. Al-Jubainawi, P. Cooper, L. D. Nghiem, Energy Build, 2016,

116, 285-295, doi: 10.1016/j.proeng.2017.10.318.

[1] L. Pérez-Lombard, J. Ortiz, C. Pout, Energy Build, 2008, 40, 394-398, doi; 10.1016/j.enbuild.2007.03.007

[2] K. A. Joudi, Q. R. Al-Amir, Energy Convers. Manag., 2014, 86, 496-506, doi: 10.1016/j.enconman.2014.05.036

[3] Z. Yang, K. Zhang, Y. Hwang, Z. Lian, Appl. Energy, 2016, $171,12-25$.

[4] A. H. Abdel-Salam, C. J. Simonson, Int. J. Refrig., 2014, 48, 166-177, doi: 10.1016/j.ijrefrig.2014.09.004

[17] X. Li, X. Zhang, Sol. Energy, 2009, 83, 2195-2204, doi: 10.1016/j.solener.2009.09.001.

[18] X. Li, X. Zhang, Energy Convers. Manag., 2012, 53, 189195, doi: 10.1016/j.enconman.2011.08.001.

[19] Q. Cheng, X., Zhang, X. Li, Energy Build, 2012, 51, 64-72, doi: 10.1016/j.enbuild.2012.04.017.

[20] Q. Cheng, X. Zhang, Energy Build, 2013, 67, 434-444, doi: 10.1016/j.enbuild.2013.08.051.

[21] X. Li, X. Zhang, S. Quan, Appl. Energy, 2011, 88, 49084917, doi: 10.1016/j.apenergy.2011.06.052.

[22] Q. Cheng, X. Zhang, S. Jiao, Energy, 2017, 140, 646-655, doi: 10.1016/j.energy.2017.09.003.

[23] H. Wang, Q. Cheng, W. Feng, W. Xu, Int. J. Refrig., 2018, 91, 189-198, doi: 10.1016/j.ijrefrig.2018.04.025.

[24] A. Ma. Z. Al-Jubainawi, Y. Guo, L. D. Nghiem, P. Cooper, W. Li, Sustain. Cities Soc., 2017, 28, 30-41, doi: 10.1016/j.scs.2016.08.021.

[25] Q. Cheng, X. Zhang, S. Jiao, Energy Build, 2017, 155, 475483, doi: 10.1016/j.enbuild.2017.09.055

[26] M. R. Conde, Int. J. Therm. Sci., 2004, 43, 367-382.

[27] K. M. Chehayeb, D. M. Farhat, K. G. Nayar, J. H. Lienhard, Desalination, 2017. 420, 167-182, doi: 10.1016/j.desal.2017.07.003.

[28] X. Cui, M. R. Islam, B. Mohan, K. J. Chua, Energy, 2016, 95, 303-312, doi: 10.1016/j.energy.2015.12.032.

[29] X. H. Liu, X. Q. Yi, Y. Jiang, Energy Convers. Manag., 2011, 52, 180-190, doi: 10.1016/j.enconman.2010.06.057.

Publisher's Note: Engineered Science Publisher remains neutral with regard to jurisdictional claims in published maps and institutional affiliations. 